\title{
A Fast Track for Rural Family Physicians
}

\author{
Thomas E. Norris, MD
}

There is currently a major shortage of rural physicians in the United States. Rural US citizens should receive the same quality of care and the same access to health care as are available in urban and suburban settings for the middle and upper classes. Yet, at present, substantial and increasing differences exist in access to health care for our rural citizens. ${ }^{1}$

The overall supply of physicians has increased from 1980 to 2000, but rural areas are not sharing in the same rate of growing supply as their urban counterparts. ${ }^{2,3}$ Fundamentally, medical education and residency have not adequately emphasized preparation for the realities of rural practice, and sufficient numbers of physicians are not choosing rural sites of practice. More than 50 million citizens, or $20 \%$ of the US population, live in rural places. Logically, $20 \%$ of US physicians should live in rural sites, but only $9 \%$ of US physicians practice rurally.

As the generalist physician workforce in rural areas ages and retires, training, recruitment, and retention of replacement physicians have not occurred at a rate to support the workforce vacancies. ${ }^{4}$ This shortfall in rural providers has led to a situation in which 22 million Americans now live in federally designated rural health professions shortage areas (HPSAs), with less than 1 primary care physician per 3,500 people. For these Americans, who comprise more than $10 \%$ of the US population, access to medical care is not only inferior to that of their urban counterparts-it might be absent altogether.

The key to addressing some of the problems of rural patients lies in correcting the deficits in the physician workforce. This "fix" will require more providers who are committed to the care of these populations and who have the special skills needed for successful rural practice. ${ }^{5}$ Currently the pipeline required to create a rural family physician,

Submitted 6 December 2002.

From the Office of the Dean, the UW Physicians Network, and the Department of Family Medicine, University of Washington, Seattle. Address reprint requests to Thomas E. Norris, MD, Office of the Dean, Box 356340, University of Washington, Seattle, WA 98195-6340. from college graduation to placement after residency, is at least 7 years. At the end of 7 years, many family practice residency graduates still lack the specialized, appropriate training for rural practice that will help assure their retention in rural areas. Yet the pipeline is even longer if specialized rural training is sought after residency. ${ }^{6}$

The article by Stageman and colleagues ${ }^{7}$ in this of the fournal describes an effort to place specially prepared family physicians into rural practice in the same 7 years that most family practice residents spend in preparation for undifferentiated practice. Such efforts have the capacity to create both a one-time surge, as well as a potential long-term gain, in the number of practicing rural family physician. An apt metaphor for this process is the financial bonus that accrues to a practice that successfully decreases the number of days in its accounts receivable queue. Not only is there a onetime gain of cash, but the practice also gets paid faster for all future transactions. Shortening the time required for specially designed rurally oriented training for family physicians, while maintaining the quality of that training, can pay similar dividends for the underserved rural communities that are counting on medical education programs to provide both replacements and help for their aging family physicians. Additionally, rural physicians who do not constantly feel that they are practicing at the "edge of their envelope" (to use an aviation metaphor) are more likely to remain in practice in rural sites. ${ }^{5}$

Accelerated training has been successfully employed previously in the education of family physicians. In 1991 the American Board of Family Practice approved 12 programs for participation in an experiment combining the fourth year of medical school with the first year of a family practice residency. While these programs had a few problems, the overall outcome was positive. In a report written 5 years into the experiment, the accelerated residents out-performed their peers on in-training examinations, and their clinical skills were rated as equal to or better than their peers in the standard length training. ${ }^{8}$ 
The training program described in this issue applies similar methodology to residents who are focusing on rural practice. If successful, accelerated, rurally oriented residency programs have great potential in helping to alleviate the severe shortages of rural family physicians.

\section{References}

1. Schur, Claudia L, Franco, Sheila J. Access to health care. In: Ricketts TC III, editor. Rural health in the united states. New York: Oxford University Press, 1999:25-37.

2. Salsberg ES, Forte GJ. Trends in physician workforce, 1980-2000. Health Affairs (Millwood) 2002; 21:165-73.

3. Physician distribution and health care challenges in rural and inner-city areas: Council on Graduate Medical Education, tenth report. Rockville, Md: US
Department of Health and Human Services, Public Health Service, Health Resources and Services Administration, 1998. (DHHS publication: HRSA. 9744.)

4. Stearns JA, Stearns MA. Graduate medical education for rural physicians: curriculum and retention. J Rural Health 2000;16:273-7.

5. Norris TE, Coombs JB, Carline J. An educational needs assessment of rural family physicians. J Am Board Fam Pract 1996;9:86-93.

6. Norris TE, Acosta DA. A fellowship in rural family medicine: program development and outcomes. Fam Med 1997;29:414-20.

7. Stageman JH, Bowman RC, Harrison JD. An accelerated rural training program. J Am Board Fam Pract 2003;16:124-30.

8. Galazka SS, Zweig S, Young P. A progress report on accelerated residency programs in family practice. Acad Med 1996;71:1253-5. 